\title{
A COMPARISON OF MOLONEY'S DARN REPAIR AND LICHTENSTEIN MESH HERNIOPLASTY FOR OPEN INGUINAL HERNIA REPAIR
}

\author{
Ankit Mohan Das ${ }^{1}$, Namita Nigam², Vijay Mohan Das ${ }^{3}$
}

\section{HOW TO CITE THIS ARTICLE:}

Ankit Mohan Das, Namita Nigam, Vijay Mohan Das. “A Comparison of Moloney's Darn Repair and Lichtenstein Mesh Hernioplasty for Open Inguinal Hernia Repair”. Journal of Evolution of Medical and Dental Sciences 2014; Vol. 3, Issue 45, September 18; Page: 10992-10999, DOI: 10.14260/jemds/2014/3434

ABSTRACT: BACKGROUND: Lichtenstein mesh repair (LMR) and Moloney's darn repair (MDR) are commonly practiced repairs for inguinal hernias with acceptably low recurrence rates. Mesh repair is considered more recent than darn repair and both of them are tension free. AIMS AND OBJECTIVE: To compare operative parameters such as surgical time, hospital stay, cost effectiveness of the procedure and post-operative parameters such as hematoma formation and recurrence between patients undergoing MDR and LMR procedures. MATERIALS AND METHODS: The study was conducted at Department of Surgery, Major S. D. Singh Medical College \& Hospital, Farrukhabad from 1st September 2013 to 1st September 2014. A total of 30 patients were selected. 15 patients were treated with MDR (Group 1) and 15 with LMR (Group 2). Cases were followed up for 1, 4, 8 and 16 weeks of discharge. The study design was comparative and prospective. RESULTS: The mean hospital stay was 7.87 days in group 1 and 7.13 days in group 2. The mean operative time was 44.9 minutes in group 1 and 39.6 minutes in group 2. Mean operating time and mean hospital stay were lower in group 2, yet the difference between two groups was significant only for mean operating time $(\mathrm{p}<0.001)$. The total number of postoperative complications were reported in 2 patients. Postoperative complication like hematoma formation occur in MDR as well as in LMR. There were no recurrences noted till date in any of the two groups under study. The cost of darn repair (group 1) was significantly less than that of mesh repair (group 2). CONCLUSION: Both LMR and MDR resulted in less complication, rapid recovery and no recurrence rates. In view of the poor socioeconomic status of the patients attending our hospital, the darn was superior to mesh in cost effectiveness.

KEYWORDS: Lichtenstien mesh repair (LMH), Moloney darn repair (MDR), inguinal hernia.

INTRODUCTION: Inguinal hernia is the most common type of hernia, comprising of approximately $75 \%$ of all anterior abdominal wall hernias. ${ }^{1}$ Hernias are common health problem; the incidence is 3$4 \%$ in male population. Hernia in inguinal region account for approximately $75 \%$ of all forms of hernias and are more common in males than females. ${ }^{2}$

The indirect inguinal hernia are more common than direct type accounting for $2 / 3$ of inguinal hernias. ${ }^{3}$ The most important recent innovation made in 1986 is by Lichtenstein ${ }^{4}$ who described the tension free repair using a polypropylene mesh for reinforcement of the posterior wall and the Laparoscopic mesh repair is becoming popular in recent days. ${ }^{5,6}$

These patients must be thoroughly evaluated before hernia repair ${ }^{7}$. The darn repair originally described by Moloney et al. is another effective technique for repairing inguinal hernia ${ }^{8}$ Darn originally described by Moloney et al, is a cheap and effective way of repair. The recurrence rate reported from original series was $0.8 \% .^{9}$ 
More recently the use of polypropylene mesh has become popular, largely because of excellent results reported by Lichtenstein et al. The recurrence rate with this procedure was reported as nil in Lichtenstein personal series but about $1 \%$ in other series. ${ }^{9}$

Because of poor socioeconomic status, non-affordability of patients and non-availability of mesh in small cities, in this study Darn technique was chosen to ascertain its effectiveness, postoperative complications and recurrence by comparing it with Lichenstein (mesh) repair. The aim of this trial was to determine any key benefit from using the mesh as opposed to the more commonly used Moloney Darn repair.

MATERIAL AND METHODS: This comparative and prospective study was conducted in department of surgery in Major S. D. Singh medical college and hospital in Farrukhabad, from 1st September 2013 to 1 st September 2014. The sample consist of 30 patients [15 cases were managed by Lichtenstein tension free hernioplasty (mesh) and 15 cases were managed by Moloney prolene darn repair].

All male patients of above 16 years of age with a clinical diagnosis of inguinal hernia for elective surgery were included in the study. Male patients under 16 years of age, female patients and patients undergoing emergency surgery for hernia were excluded from the study. Base line and specific investigations for pre-anesthesia assessment were carried out. The patients were randomized into two groups according to the technique of posterior wall repair;

Group 1: In this group posterior wall repair was done by Moloney's prolene darn.

Group 2: In this group posterior wall repair was done by Lichtenstein mesh repair.

The repair procedures were explained to all patients and duly signed, informed consent was obtained from them. All patients received a single dose of intravenous injection of ceftriaxone (1000 $\mathrm{mg}$ ) at onset of anesthesia, followed by postoperative doses. The anesthesia was spinal.

A skin crease approach following Langer's line was adopted in all cases. The incision was deepened, tackling subcutaneous neuro-vascular structures as usual till the external oblique aponeurosis was reached. The resulting slit was about an inch above the inguinal ligament, which provided a large lower leaf for optimal closure.

A gentle sweeping action with the index finger under the aponeurosis helps to open this plane widely for an adequate darn or mesh insertion. The cremasteric fascia was always incised which helped mobilize the cord structures properly. A direct sac was always pushed back and an indirect sac ligated at its neck by absorbable (vicryl) no; 1 suture and then excised $1 \mathrm{~cm}$ distal to the ligature, and the fascia transversalis repaired with no; 1 loosely wound continuous prolene sutures.

In the "mesh" group, a sheet of polypropylene mesh $(11 \times 6 \mathrm{~cm})$ was trimmed to fit the adequately dissected out space, with a slit cut laterally to accommodate the spermatic cord. The mesh overlapped the pubic tubercle by 1-2 $\mathrm{cm}$ medially and superiorly extended over the conjoint tendon to lay 2-3 cm lateral to the internal ring.

The mesh was then fixed in position by interrupted 2-0 prolene sutures starting along the internal surface of the inguinal ligament infero-medially and continuing laterally as far as the incision would allow. Three to four interrupted stitches helped fix the mesh superiorly.

The two tails were now overlapped lateral to the internal ring and secured by two to three interrupted sutures making sure that the cord was not constricted; figure 1. 


\section{ORIGINAL ARTICLE}

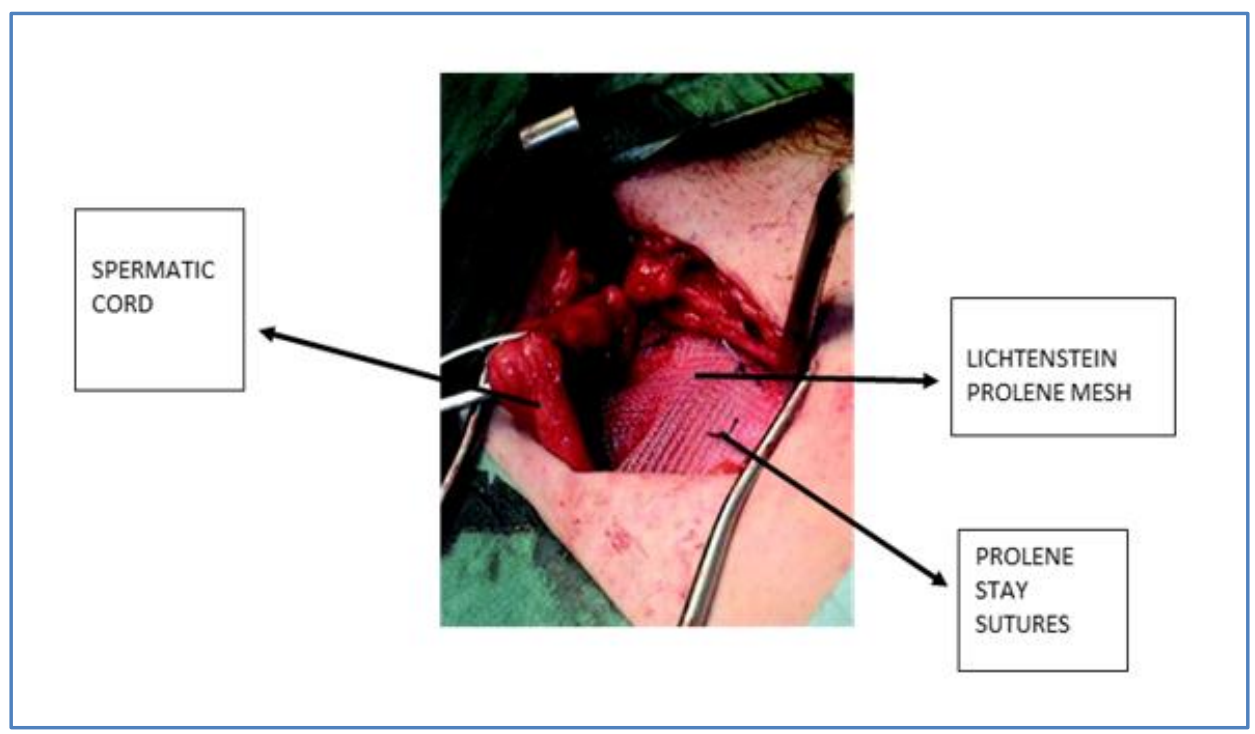

Fig. 1

In the "darn" group, no;1 prolene suture was used to reconstruct the inguinal bed with a tension-free darn starting with a good strong bite of the tough tendinous structures near the pubic tubercle and emerging out through the lateral edge of the rectus sheath with a bulky bite in between.

The loosely interwoven bites continued laterally and the back-forming two rows of continuous stitches were placed in a staggered manner to spread the tension between the fibres of the inguinal ligament. The recurrence hotspot, "the critical medial angle", was repaired meticulously in each case. The Aberdeen knot was used to avoid a thick nylon knot at the end. A gap of 0.5-1 cm was maintained between the stitches to obtain a closely knit darn; FIGURE 2.

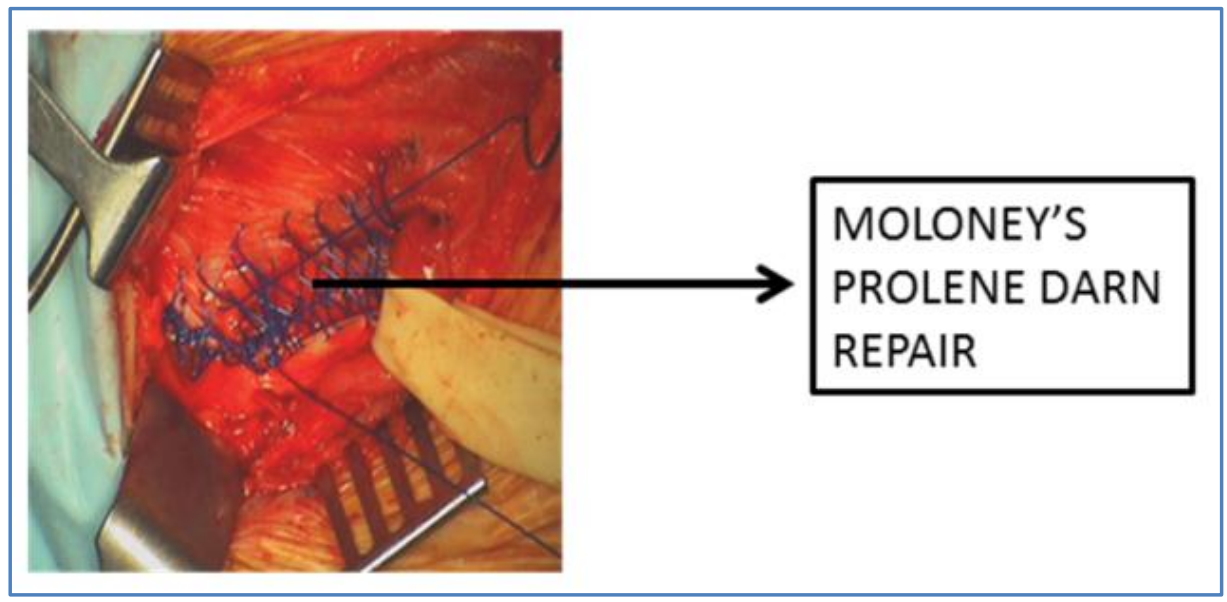

Fig. 2

In both the groups, having checked for hemostasis meticulously and after replacing the safeguarded iliohypogastric nerve and the cord structures, the external oblique aponeurosis was closed with 1-0 continuous vicryl suture. 
The skin was opposed using 2-0 simple interrupted mersilk sutures. Operative time taken from skin incision to skin closure was recorded in all cases of both groups. Patients of both groups were routinely given systemic analgesic in the $1^{\text {st }} 24 \mathrm{hr}$., which was diclofenac sodium i.m. inj. $75 \mathrm{mg}$, if pain was not relieved tramadol i.m. inj. $100 \mathrm{mg}$ was given.

They were advised to continue on oral analgesics for $72 \mathrm{~h}$ into the postoperative period. All patients were observed for 24 hours and were discharged only when they emptied their bladders and felt comfortable and confident with themselves. The first reviews on the patients of both groups were carried out on the $7^{\text {th }}$ postoperative day ( $1^{\text {st }}$ week).

Detailed records were kept concerning their early postoperative complications in the form of superficial surgical site infections, scrotal indurations, testicular atrophy, neuralgia, mesh/darn infection requiring withdrawal and recurrence. Stitches were removed on the $10^{\text {th }}$ post- operative day for all, except those who experienced early wound complications.

Patients were followed up at $4^{\text {th }} 8^{\text {th }}$ and $16^{\text {th }}$ week post operation and evaluated for any residual complications and recurrence. Statistical analysis was done using SPSS (Statistical Package For Social Sciences) Version 15.0 and analysis perform using the ' $t$ ' test, chi square test and ' $p$ ' probability were calculated.

RESULTS: 30 patients were evaluated. Total of 15 (50\%) were placed in Group 1 and remaining 15 (50\%) in Group 2, TABLE 1. Age of patients ranged from 19 to 46 years. Majority of patients in both groups were between 21-40 years.1 patient from each group was aged upto 20 years. Mean age of patients in group 1 was $31.93 \pm 7.89 y$ rs and in group2 was 33.3 $\pm 7.22 y$ rs. There was no significant difference between the two groups $(\mathrm{p}=0.475)$ TABLE 2. Majority of subjects in group1 were clerk, teacher and shopkeepers (53.3\%) whereas majority of subjects in group 2 were laborers (53.3\%).There was no significant difference between two groups ( $\mathrm{p}=0.577)$.TABLE 3.

The mean operative time was 44.9 minutes in group 1 and 39.6 minutes in group 2 . The mean hospital stay was 7.13 days in group 1 and 7.87day in group 2.Both mean operating time and mean hospital stay were lower in Group 2 as compared to Group 1, yet the difference between two groups was significant only for mean operating time $(\mathrm{p}<0.0001)$ TABLE 4.

At first week follow up, none of the cases had infection, all subjects had moderate pain while hematoma formation was observed in both groups (6.7\%).Statistically, there were no significant difference two groups TABLE 5. At second follow up all the patients in both the groups had mild pain. None of the cases had hematoma formation TABLE 6.At third month, none of the patients had infection, pain or hematoma formation TABLE 7. There was no difference in outcome of two groups TABLE 8.

\begin{tabular}{|c|c|l|c|c|}
\hline $\begin{array}{c}\text { Sl. } \\
\text { No. }\end{array}$ & Group & \multicolumn{1}{|c|}{ Details } & $\begin{array}{c}\text { No. } \\
\text { of cases }\end{array}$ & Percentage \\
\hline 1 & 1 & $\begin{array}{l}\text { Patients in whom inguinal hernia } \\
\text { was repaired using Moloney Darn repair }\end{array}$ & 15 & 50 \\
\hline 2 & 2 & $\begin{array}{l}\text { Patients in whom inguinal hernia was repaired } \\
\text { using Lichtenstein mesh hernioplasty }\end{array}$ & 15 & 50 \\
\hline \multicolumn{4}{|r|}{ TABLE 1: Group wise distribution of subjects } \\
\hline \multicolumn{4}{|r|}{} \\
\hline \multicolumn{4}{|c|}{}
\end{tabular}




\begin{tabular}{|c|c|c|c|c|c|}
\hline \multirow{2}{*}{$\begin{array}{c}\text { Sl. } \\
\text { No. }\end{array}$} & \multirow{2}{*}{$\begin{array}{c}\text { gge } \\
\text { group }\end{array}$} & \multicolumn{2}{c|}{ Group 1 (n=15) } & \multicolumn{2}{c|}{ Group 2 (n=15) } \\
\cline { 3 - 6 } & NO. & \% & N0. & \% \\
\hline 1 & $<=20$ & 1 & 6.7 & 1 & 6.7 \\
\hline 2 & $21-30$ & 5 & 33.3 & 4 & 26.7 \\
\hline 3 & $31-40$ & 5 & 33.3 & 7 & 46.7 \\
\hline 4 & $41-50$ & 4 & 26.7 & 3 & 20.0 \\
\hline \multicolumn{3}{|c|}{ TABLE 2: Age wise distribution of subjects }
\end{tabular}

\begin{tabular}{|c|c|c|c|c|c|}
\hline \multirow{2}{*}{$\begin{array}{l}\text { Sl. } \\
\text { No. }\end{array}$} & \multirow{2}{*}{ Occupation } & \multicolumn{2}{|c|}{ Group $1(n=15)$} & \multicolumn{2}{|c|}{ Group $2(n=15)$} \\
\hline & & NO. & $\%$ & NO. & $\%$ \\
\hline 1 & Unemployed & 1 & 6.7 & 1 & 6.7 \\
\hline 2 & Laborer & 5 & 33.3 & 8 & 53.3 \\
\hline 3 & $\begin{array}{l}\text { Clerical/Teachers/ } \\
\text { Shopkeepers }\end{array}$ & 8 & 53.3 & 6 & 40.0 \\
\hline 4 & Administrative job & 1 & 6.7 & 0 & 0.0 \\
\hline
\end{tabular}

\begin{tabular}{|c|l|c|c|c|c|c|c|}
\hline \multirow{2}{*}{$\begin{array}{c}\text { Sl. } \\
\text { No. }\end{array}$} & \multirow{2}{*}{ Parameters } & \multicolumn{2}{|c|}{$\begin{array}{c}\text { Group 1 } \\
(\mathbf{n = 1 5 )}\end{array}$} & \multicolumn{2}{c|}{$\begin{array}{c}\text { Group 2 } \\
\text { (n=15) }\end{array}$} & \multicolumn{2}{c|}{$\begin{array}{c}\text { Significance of } \\
\text { difference }\end{array}$} \\
\cline { 3 - 8 } & & Mean & SD & Mean & SD & t & p \\
\hline 1. & $\begin{array}{l}\text { Operating time } \\
\text { (minutes) }\end{array}$ & 44.9 & 2.42 & 39.6 & 1.72 & 6.87 & $<0.001$ \\
\hline 2. & $\begin{array}{l}\text { Hospital stay } \\
\text { (days) }\end{array}$ & 7.13 & 0.74 & 7.87 & 0.92 & 0.876 & 0.389 \\
\hline
\end{tabular}

\section{TABLE 4: Comparison of two groups for operating time and hospital stay}

\begin{tabular}{|c|l|c|c|c|c|}
\hline \multirow{2}{*}{$\begin{array}{c}\text { Sl. } \\
\text { No. }\end{array}$} & \multicolumn{2}{|c|}{ Variable } & \multicolumn{2}{c|}{ Group 1 (n=15) } & \multicolumn{2}{c|}{ Group 2 (n=15) } \\
\cline { 2 - 6 } & & NO. & $\mathbf{\%}$ & NO. & \% \\
\hline 1 & Infection & 0 & 0 & 0 & 0 \\
\hline 2 & Pain & & & & \\
\hline & Mild & 0 & 0 & 0 & 0 \\
\hline & Moderate & 15 & 100 & 15 & 100 \\
\hline & Severe & 0 & 0 & 0 & 0 \\
\hline 3 & Hematoma formation & 1 & 6.7 & 1 & 6.7 \\
\hline \multicolumn{4}{|r|}{ TABLE 5: First follow up findings } \\
\end{tabular}




\begin{tabular}{|c|c|c|c|c|c|}
\hline \multirow{2}{*}{$\begin{array}{c}\text { Sl. } \\
\text { No. }\end{array}$} & \multirow{2}{*}{ Variable } & \multicolumn{2}{|c|}{ Group $1(n=15)$} & \multicolumn{2}{|c|}{ Group $2(n=15)$} \\
\hline & & NO. & $\%$ & NO. & $\%$ \\
\hline 1 & Infection & 0 & 0 & 0 & 0 \\
\hline \multirow[t]{4}{*}{2} & Pain & & & & \\
\hline & Mild & 15 & 100 & 15 & 100 \\
\hline & Moderate & 0 & 0 & 0 & 0 \\
\hline & Severe & 0 & 0 & 0 & 0 \\
\hline 3 & Hematoma formation & 0 & 0 & 0 & 0 \\
\hline
\end{tabular}

\begin{tabular}{|c|l|c|c|c|c|}
\hline \multirow{2}{*}{$\begin{array}{c}\text { Sl. } \\
\text { No. }\end{array}$} & \multicolumn{1}{|c|}{ Variable } & \multicolumn{2}{c|}{ Group 1 (n=15) } & Group 2 (n=15) \\
\cline { 2 - 6 } & & NO. & \% & NO. & \% \\
\hline 1 & Infection & 0 & 0 & 0 & 0 \\
\hline 2 & Pain & 0 & 0 & 0 & 0 \\
\hline & Mild & 0 & 0 & 0 & 0 \\
\hline & Moderate & 0 & 0 & 0 & 0 \\
\hline & Severe & & & & \\
\hline 3 & Hematoma formation & 0 & 0 & 0 & 0 \\
\hline \multicolumn{5}{|r|}{ TABLE 7: Third follow up findings } \\
\hline
\end{tabular}

\begin{tabular}{|c|l|c|c|c|c|}
\hline Sl. & \multirow{2}{*}{ Variable } & \multicolumn{2}{c|}{ Group 1(n=15) } & \multicolumn{2}{c|}{ Group 2(n=15) } \\
\cline { 3 - 6 } No. & & No. & $\mathbf{\%}$ & No. & $\mathbf{\%}$ \\
\hline 1 & Recurrence & 0 & 0 & 0 & 0 \\
\hline 2 & Patient satisfaction & 15 & 100 & 15 & 100 \\
\hline 3 & Operator satisfaction & 15 & 100 & 15 & 100 \\
\hline \multicolumn{6}{|c|}{ TABLE 8: Outcome of surgery } \\
\hline
\end{tabular}

DISCUSSION: Operations for hernias constitute approximately $10-15 \%$ of all surgical procedures performed in a general surgical unit and about $80 \%$ of these operations are performed for inguinal hernias. ${ }^{10}$ It is the most common surgical procedure after appendicectomy. ${ }^{11}$

In recent years, the synthetic mesh has replaced the conventional method worldwide (used through open or laparoscopic technique).12 These methods are associated with rapid return to normal activities with low recurrence rates. ${ }^{13}$ There are many ways of repairing an inguinal hernia, with over 80 operative techniques described since 1887 when Bassini reported his method.

Extensive clinical research has been undertaken to assess outcome following inguinal hernia repair. ${ }^{14}$ The basic defect lies in the anterior abdominal wall that allows hernia in relation to a deficiency in fascia transversalis. So repair of hernia must include restoration of this layer, which constitutes the posterior wall repair. ${ }^{15}$ 
In our study the patients were randomized to two group's i-e group 1: underwent Moloney darn repair \& group 2: Mesh repair. In present study the peak incidence during $3^{\text {rd }}$ and $4^{\text {th }}$ decades of age. Shah et al. (2011) ${ }^{16}$ too reported a similar incidence in their study. In Group 1, 15 patients underwent Moloney darn repair. The mean operative time was 44.9 minutes. Boonnithi et al. $(2010)^{17}$ reported a mean time of 46.1 minutes for darn repair. In Group 2, 15 patients underwent Lichtenstein mesh repair.

The mean operative time was 39.6 minutes. Boonnithi et al. (2010) ${ }^{17}$ reported a mean time of 42.7 minutes for mesh repair. In group 1 mean hospital stay was 7.13 days whereas same was 7.87 days in group 2.Boonnithi et al (2010) ${ }^{17}$ have reported the mean duration of hospital stay to be 2.3 days for darn repair and 2.2 for mesh repair.

The longer duration of hospital stay in present study is as we have included both preoperative and post-operative hospital stay and majority of the subjects were from lower socioeconomic status i.e. manual laborers or petty vendors, hence it was considered appropriate that the hospital stay might be extended to provide a better post-operative care and thus reduce the impending threat of post-operative infection.

In both group1 and group 2 total numbers of complications were 1(6.7\%) each (hematoma). Boonnithi et al (2010) ${ }^{17}$ reported the incidence of hematoma formation in $1(1.4 \%)$ of darn repair and 3 (5.1\%) of mesh repair. The method of hernia repair in both groups did not affect the length of hospital stay which was 7 days in group $1 \& 2$. It was also reflected in our study that patients who underwent Moloney's Darn repair returned to the routine activities in almost same period as the patients with mesh repair did.

CONCLUSION: It was concluded that both Moloney Darn and Lichtenstein mesh repair showed an equal efficacy, resulted same complication, rapid recovery and no recurrence rate. However, considering the cost of procedures, Darn's repair cost only Rs100/- while Lichtenstein's repair cost around Rs 1500/-.So we can say mesh repair of primary inguinal hernias is not so much superior to non-mesh repair with regard to inguinal hernia repair and in view of the poor socioeconomic status of the patients attending our hospital, Darn's repair is the preferred procedure.

\section{REFERENCES:}

1. Primatesta P, Golacre MJ. Inguinal hernia repair, incidence of elective and emergency surgery. Int J Epidemol 1996; 25: 835-9.

2. Wantz GE. Abdominal wall hernias. In: Schwartz SI ed. Principles of surgery. New York McGraw Hill 1999; 7, 1585-611.

3. Eubanks WS. Hernias. In: Townsend CM ed. Sabiston textbook of surgery. The biological basis of modern surgical practice. Philadelphia WB Saunders 2001; 6, 783-801.

4. Lichtenstein IL, Shulman AG. Ambulatory outpatient hernia surgery, including new concept, introducing tension-free repair. Int Surg 1986; 71:1-4.

5. Cuschieri A. Disorders of abdominal wall and peritoneal cavity. In: Cuschieri Essential Surgical Practice 4TH ed. London: Arnold (Hodder Headline Group); 2002; I: 143 - 45.

6. Lal P, Kajla RK. Laparoscopic total extraperitoneal versus open Lichtenstein inguinal hernia repair. J Surg Endosc; 2003 June: 850 - 6.

7. Mayor-Davis-JA. Groin hernia-beware! S Afr J Surg. 1990 Mar; 28 (1): 20. 
8. Moloney G. Darning in inguinal hernias. Ach Surg.1972; 104: 129.

9. Koukourou A, Lyon W, Rice J, Waltchow DA. Prospective randomized trial of polypropylene mesh with nylon darn in inguinal hernia repair. Br J Surg 2001; 88, 931-4.

10. Malik ZI, Ahmad E, Ayub GH, Khan SH. Lichtenstein repair. J Surg PIMS 1993; 5: 18-9.

11. Bhatti AZ, Rasool MI. Darning vs. Bassini repairs in primary unilateral inguinal hernia. J Coll Phys Surg Pak 2002; 12, 169-71.

12. EU Hernia Trialists Collaboration. Repair of groin hernia with synthetic mesh: meta-analysis of randomized controlled trials. Ann Surg. 2002; 235 (3): 322-332.

13. EU Hernia Trialists Collaboration. Mesh compared with non-mesh methods of open groin hernia repair: systematic review of randomized controlled trials. Br j Surg 2000; 87: 854-9.

14. Bendavid R. New techniques in hernia repair. World J Surg 1989; 13, 522-31.

15. Bhopal FG, Niazi GHK, Iqbal M. Evaluation of Lichtenstein repair for morbidity and recurrence. J Surg Pak 1998; 3, 202.

16. Shah A, Amanullah A, Wazir F. Outcome of inguinal hernia repair with Lichtenstein technique. Gomal journal of medical sciences 2011; 9 (1):98-100.

17. Boonnithi N, Kongkham K.A prospective clinical trial comparing Darn versus Bassini versus Lichtenstein inguinal herniorrhaphy. The THAI journal of SURGERY 2010; 31: 125-129.

\section{AUTHORS:}

1. Ankit Mohan Das

2. Namita Nigam

3. Vijay Mohan Das

\section{PARTICULARS OF CONTRIBUTORS:}

1. Assistant Professor, Department of General Surgery, Major S. D. Medical College and Hospital, Farrukhabad.

2. Assistant Professor, Department of Gynaecology and Obstetrics, Major S. D. Medical College and Hospital, Farrukhabad.

3. Assistant Professor, Department of General Surgery, Major S. D. Medical College and Hospital, Farrukhabad.

\section{NAME ADDRESS EMAIL ID OF THE CORRESPONDING AUTHOR: \\ Dr. Ankit Mohan Das, \\ $1 / 139$, Talaya Lane, \\ Near Bank of India, \\ Fatehgarh District, \\ Farrukhabad-209601, U. P. \\ Email: dr.ankitdas@gmail.com}

Date of Submission: 05/09/2014.

Date of Peer Review: 06/09/2014.

Date of Acceptance: 11/09/2014.

Date of Publishing: 16/09/2014. 